\title{
Heterogeneous Catalysis with the Participation of Ionic Liquids
}

\author{
Olga Bartlewicz ${ }^{1}$ (), Izabela Dąbek ${ }^{2}$, Anna Szymańska ${ }^{2}$ (1) and Hieronim Maciejewski ${ }^{1,2, *}$ (1) \\ 1 Faculty of Chemistry, Adam Mickiewicz University, Uniwersytetu Poznańskiego 8, 61-614 Poznań, Poland; \\ olga.bartlewicz@amu.edu.pl \\ 2 Adam Mickiewicz University Foundation, Poznań Science and Technology Park, Rubież 46, \\ 61-612 Poznań, Poland; Izabela.Dabek@ppnt.poznan.pl (I.D.); Anna.Szymanska@ppnt.poznan.pl (A.S.) \\ * Correspondence: hieronim.maciejewski@amu.edu.pl
}

Received: 30 September 2020; Accepted: 20 October 2020; Published: 22 October 2020

\begin{abstract}
This mini-review briefly describes the recent progress in the design and development of catalysts based on the presence of ionic liquids. In particular, the focus was on heterogeneous systems (supported ionic liquid (IL) phase catalysts (SILPC), solid catalysts with ILs (SCILL), porous liquids), which due to the low amounts of ionic liquids needed for their production, eliminate basic problems observed in the case of the employment of ionic liquids in homogeneous systems, such as high price, high viscosity, and efficient isolation from post-reaction mixtures.
\end{abstract}

Keywords: heterogeneous catalyst; SILPC; SCILL; porous ionic liquids

\section{Introduction}

Over the last few decades, ionic liquids (ILs) have undoubtedly been among the most rapidly developing and has attracted great interest as chemical compounds. Due to their special properties and a wide spectrum of applications, ionic liquids were chosen a few years ago as one of 20 materials with the highest application potential [1]. Directions of their applications are very diverse-from solvents as an alternative to volatile organic solvents, through electrochemistry (as electrolytes and conducting polymers), chemical separation, liquid and solid carriers, surfactants, and stabilizers of nanoparticles to catalysis in a broad sense (as catalysts, co-catalysts, catalyst supports, and adjuvant substances). It is no wonder that, currently, the number of publications on ionic liquids exceed 100,000 (104,310 on 23 September 2020) and, each year, about 9000 new reports appear (Figure 1) [2].

Among them, there are many excellent review papers and books on the properties and applications of ionic liquids [3-7].

Such great and continued interest in ionic liquids result mainly from their unique properties, as well as their evolution and adjustment to the new requirements and expectations. One can see that, after the first report on ionic liquids [8], as much as 40 years had passed until the appearance of ionic liquids of practical significance. These were chloroaluminate-based liquids [9] and, later, also ILs based on other metallates, so-called first-generation (Figure 2), which could be applied to electrochemistry, as well as to the electrolytic deposition of metals.

Unfortunately, chloroaluminates due to their great moisture sensitivity and instability required special conditions to use them, which significantly limited areas of their applications. After the next 40 years, the second generation of ionic liquids appeared that were stable both in air and moisture environments [10], which resulted in the rapid development of research on the properties and new directions of the applications of ionic liquids. 


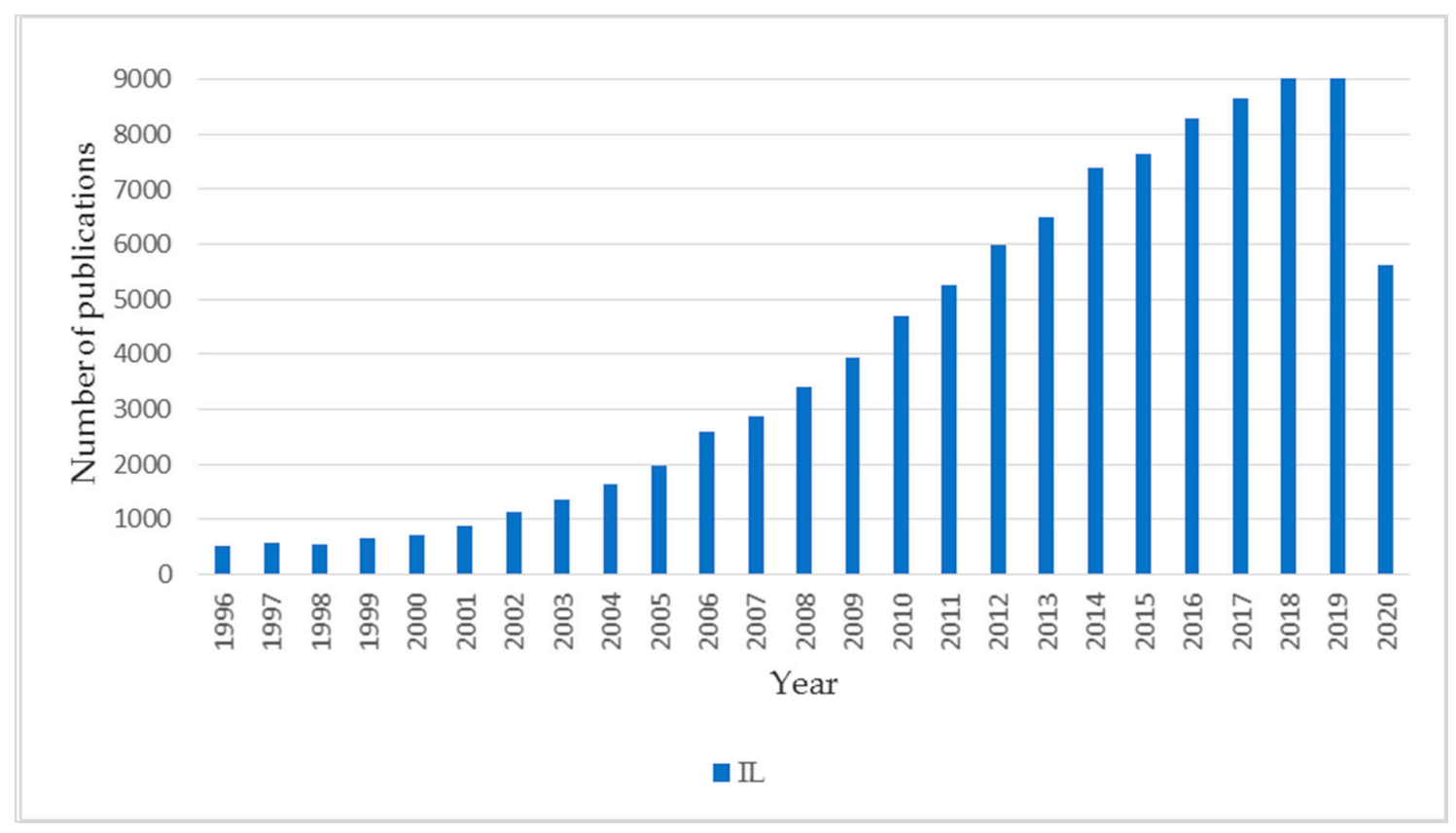

Figure 1. Number of publications on ionic liquids in the period 1996-2020.

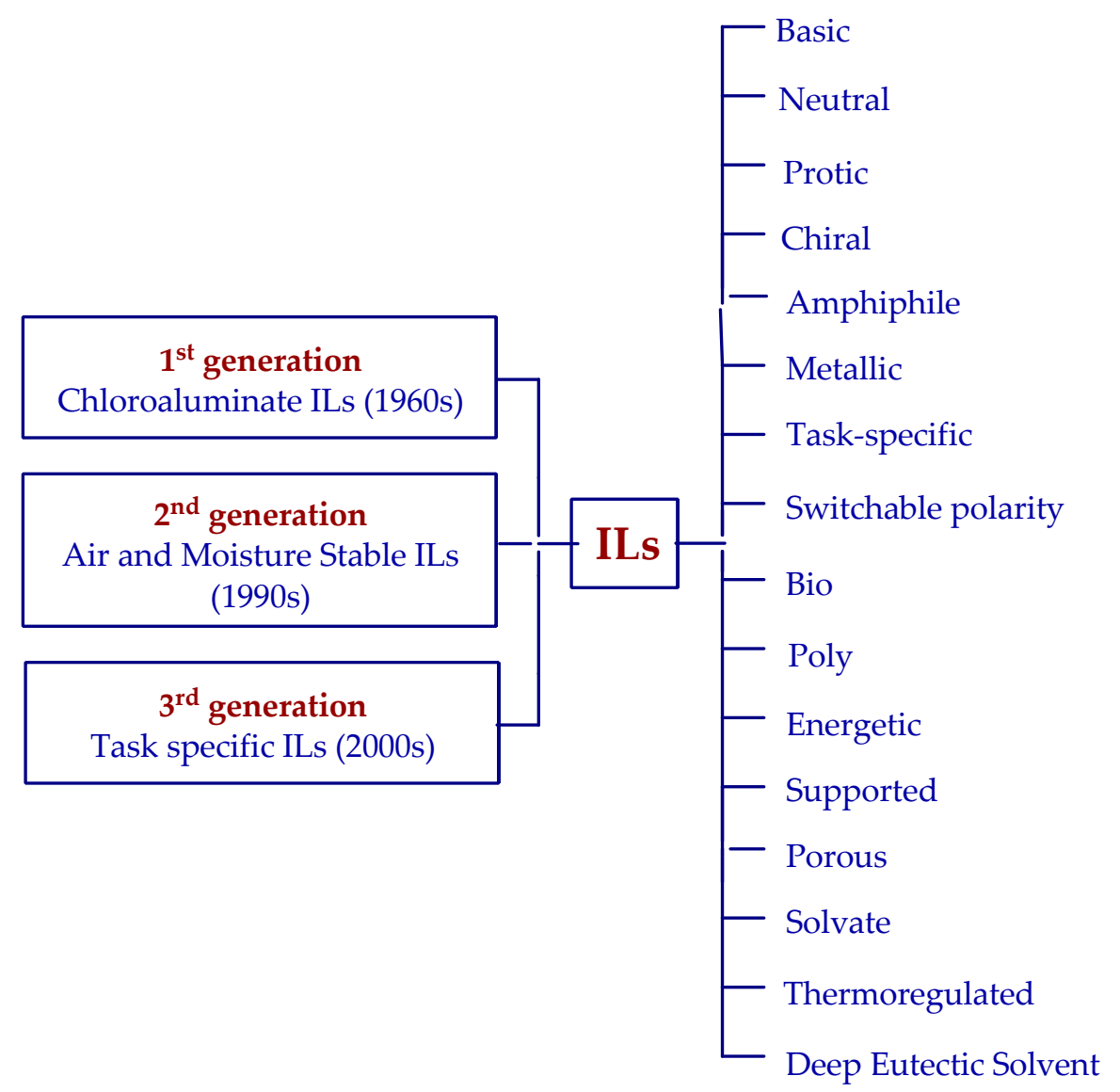

Figure 2. Structural evolution of the respective generations of ionic liquids. 
The constantly developing knowledge leads to the design of new ILs that have specific properties and can be dedicated to particular tasks (task-specific ILs) [11]. This is the third generation of ionic liquids. The stages of the evolution of ILs have been very recently perfectly collected and presented by Welton [12]. However, the evolution of ionic liquids primarily finds its reflection in the permanent development and perfection of their properties, as well as in the adjustment to the required needs. At the end of the last century, the most frequently highlighted feature of ionic liquids was their low vapor pressure and high thermal stability, which should make them a green alternative to commonly used organic solvents. However, with the beginning of the new millennium, increasingly more critical opinions have been expressed that point to the toxicity, low biodegradability (or lack thereof), complicated or, in many cases, waste-generating synthesis, as well as high costs, of the manufacture of ILs [13-18]. All these voices made the term "green alternative" depreciate. However, due to the ability of ILs to evolve, after a short period of stagnation, publications of studies intended for the improvement of synthesis methods, the utilization of biodegradable and nontoxic raw materials, considerable reduction in waste, etc. began to appear [19]. One of the examples of such an approach is the application of ultrasound or microwave radiation in the synthesis of ionic liquids, which resulted in the acceleration of reactions, reduced energy inputs, and decrease in the reagent amount (compared to traditional methods), and especially, the mentioned radiation influences the selectivity of processes and waste reduction [20-23]. In addition, the approach has changed to the choice of raw materials for syntheses, which increasingly more often, are compounds originating from biorenewable sources. To this end, derivatives of choline and lignins are frequently employed as precursors of cations, whereas carboxylates of fatty acids, levulinates, and lactates are precursors of anions [24-30]. Moreover, studies are conducted on the properties of solvents and their effect on the environment and health safety, which enables their conscious and safe use [31]. Nevertheless, the most common-sense approach to the evaluation of the reasonable application of ionic liquids is to answer the question of whether they could ensure more sustainable production and cleanliness of technology compared to conventional reagents [32]. Irrespective of this, one can say that the next stage of the adjustment of ionic liquids to the expectations and pro-environmental activities resulted in a further increase in the interest in ionic liquids and pointed to new directions of their applications. Due to the diversity of combinations of anions, cations, and the properties of ionic liquids, there exist many kinds of their classification [5-7,33,34]. An example of the structural evolution of particular generations of ionic liquids is presented in Figure 2. An intensive development can be observed among ionic liquids themselves, as well as among the compounds that are not altogether regarded as ionic liquids such as deep eutectic solvents [35-37] or solvate ionic liquids [38]. Currently, the diversity of the application directions is very large, beginning from separation techniques [39] through the production and storage of energy [40,41], different types of biotransformations [42,43], organocatalysis [44], and ending with pharmaceuticals [45] and space technology [46].

\section{Ionic Liquids in Catalysis}

Research on ionic liquids in catalysis is one of the most interesting areas of catalytic studies [24,47-49], as evidenced by the number of publications in this field, which over the last 5 years, has been increasing by over 400 reports per year (Figure 3 ).

Along with the quest for new alternative methods of the synthesis of ionic liquids with the employment of biodegradable or renewable raw materials, the development of biocatalysis based on ionic liquids began. Increasingly more interesting publications have appeared on this subject $[27,30,50-52]$.

However, one of the more important and developed wide-scale directions of applications of ionic liquids in catalysis is their use for the immobilization of homogeneous catalysts and formation of biphasic systems, where one phase is made by an ionic liquid with a catalyst dissolved in it, and the other is made by reagents. However, besides unquestionable advantages such as easier catalyst separation from the reaction mixture (e.g., by decantation and extraction) and the possibility of catalyst 
recycling and its multiple use, several disadvantages also exist: (i) A possibility of catalyst leaching from the ionic liquid, which is caused by the polarity of some reagents; (ii) the absorption of moisture and various contaminants by ionic liquid, which can result in catalyst deactivation; (iii) high viscosity of ionic liquids is often an obstacle to achieving maximum product yield; (iv) a relatively large amount of ionic liquid is necessary, and this is economically unfavorable because ionic liquids are expensive. Moreover, low vapor pressure, which is an asset of ionic liquids in the case of their employment as solvents, can be a problem when the separation of ionic liquid from the post-reaction mixture is necessary. Difficulties in the separation can also be caused by good solubility of ionic liquids in various solvents. Additionally, the high viscosity of most ionic liquids creates problems with mass transfer, which can be a factor determining the course of the catalytic reaction. Various approaches to reduce these problems are applied, e.g., too high a viscosity can be decreased by the employment of an additional solvent (co-solvent). Recently, interest was aroused in microemulsions based on ionic liquids and aqueous or nonaqueous solvents [53] that combine the functions of ILs with a considerably lower viscosity. Another possibility to facilitate the separation of biphasic systems is the application of thermo-regulated (temperature-responsive) ILs, which solidify (together with the catalyst contained in them) when the temperature decreases, and this enables easy separation from reagents. After rewarming, the system homogenizes and shows activity in subsequent reaction cycles. Recently, a review paper appeared that contains a very good presentation of this group of ionic liquids and their applications in catalysis [54]. Currently, there has a common trend to obtain heterogenized systems that combine advantages of homogeneous catalysis (high activity) and heterogeneous catalysis (easiness of isolation, possibility of employing fixed bed reactors), which makes the catalytic process more cost-effective.

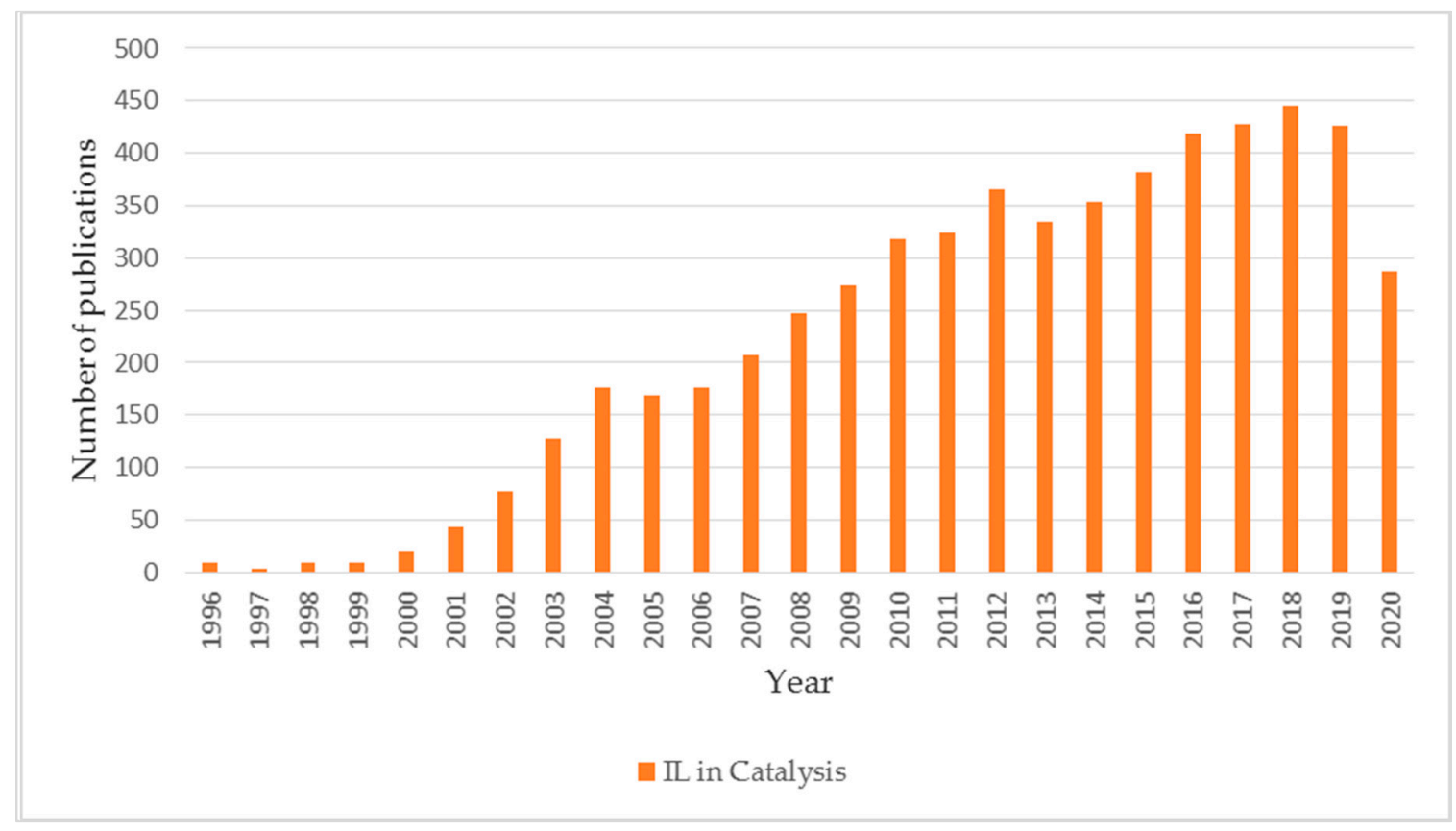

Figure 3. Number of publications on ionic liquids in catalysis in the period 1996-2020.

Such integration of homo- and heterogeneous catalysts is currently realized in several variants: Supported IL phase catalysts (SILPCs), solid catalysts with ILs (SCILLs), and supported ionic liquid catalysis (SILC). Recently, keen interest has also been seen in porous ionic liquids and metal-organic frameworks (MOFs). 


\subsection{Supported Ionic Liquid Phase Catalysts (SILPCs)}

There is a great interest in materials of this type, which is reflected by the many publications, including review papers and books [55-58].

The SILPC materials consist of three different parts, the basis of which is a porous support, most frequently silica, alumina, or active carbon. The support surface is coated with a thin layer of an ionic liquid and the third component is a catalyst such as a nanoparticle or metal complex (Figure 4).

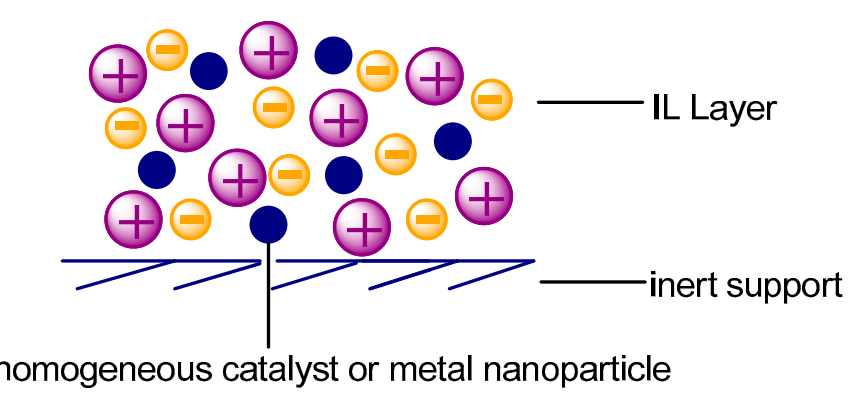

Figure 4. Model of the supported ionic liquid (IL) phase catalysts (SILPC) structure.

Different methods are used to produce materials of this type, the most important of which are the covalent anchoring method, the immersion method, and the encapsulation method [5]. The SILP systems are very popular due to the simplicity of the method of their preparation. The application of ionic liquid onto the porous support with large surface area, with or without a catalyst in the presence of a low-boiling solvent, permits the obtaining of the SILP materials [59] as a result of physical (or more rarely, chemical) adsorption. Their potential is characterized by the possibility of developing the surface with unique properties by an appropriate choice and modification of the support and ionic liquid and the addition of a catalyst. In the literature, many examples can be found on the catalytic application of the above systems; however, the vast majority of them concern the reaction of hydroformylation. The development of SILP systems applied in the reaction, as well as the development of the process itself within the last fifteen years, has been presented in the publication by Marinkovic et al. [60]. The studies carried out during the recent decades enabled the determination of conditions for conducting respective hydroformylation reactions in the liquid and gas phases, which in turn, made it possible to choose a SILP material for specific reaction conditions. One of the trends is an addition of a ligand, which together with a homogeneous catalyst, is immobilized in the SILP system, and due to this, an increase in the reaction conversion is achieved [61]. The kind and, especially, size of the employed reagent have a significant effect on the effectiveness of the SILP material used. In the case of alkenes containing less than six carbon atoms, to prevent the ionic liquid layer leaching from the surface of SILPs by the polar products formed in the system, it is recommended to employ the SILP materials in which the ionic liquid is bound to the support by a covalent bond or the application of nonpolar solvents as a mobile phase (Figure 5).

In the case of higher alkenes, a novelty is the application of supercritical carbon dioxide $\left(\mathrm{scCO}_{2}\right)$ as a mobile phase in the catalytic system with SILP materials [62]. Increasingly more often, particularly in reactions of hydroformylation of lower alkenes, catalytically active membranes are employed. Most likely, the reactors with SILP system-based membranes will soon be used that will enable them to conduct reactions in a continuous way and permit the direct separation of products and unreacted substrates (ROMEO approach-Reactor Optimization by Membrane Enhanced Operation) [63].

The SILP systems have also found applications in many other reactions. The reactions conducted in the presence of the supported ionic liquid phase were reviewed by Romanovsky and Tarkhanova, who have shown the applicational diversity of these systems [64]. The reactions in the liquid phase carried out with the use of SILPs include, among others, redox reactions, e.g., oxidation of sulfur-containing compounds [65], oxidation of phenols [66], reactions with haloalkynes $[67,68]$, as well as many 
organic syntheses such as Heck reactions [69], Suzuki reactions [70], hydroamination of unsaturated compounds [71], Sandmayer reactions [72], and isomerization of hydrocarbons [73].

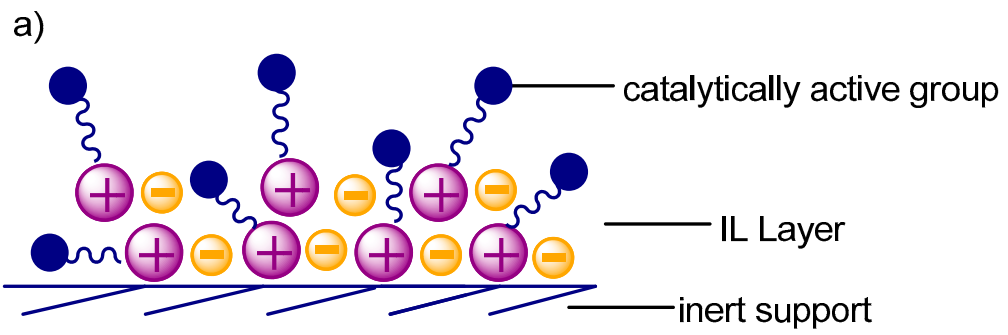

b)

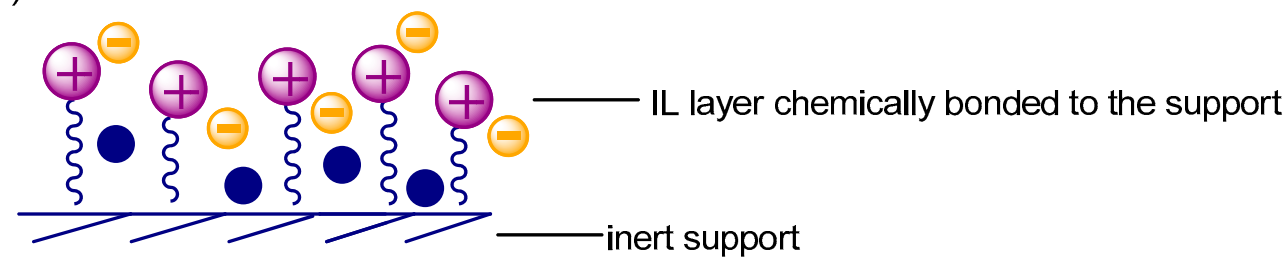

Figure 5. Methods of preventing catalyst from leaching: (a) By permanent bonding to ionic liquid; (b) by covalent bonding of ionic liquid to support.

One of the most recent novelties in the organic synthesis is the application of Pd-SILP systems with an amine group-containing imidazolium ionic liquid supported on the Merrifield resin (cross-linked chloromethyl polystyrene). The above system has been employed in the Suzuki-Miyaura coupling reaction carried out at room temperature. The reactions conducted with the use of different reagents proved that the system was stable, catalytically active, and permitted its isolation and effective reuse in five subsequent catalytic cycles [74]. Very popular are also ruthenium catalysts whose high price restricts their application to the systems that permit their recycling. An example is the preparation of SILPC systems with the use of ruthenium chloride, imidazolium ionic liquids, and activated carbon as support. The obtained system was employed in the hydrochlorination of acetylene, where the effect of the SILPC system on the improvement in conversion and selectivity was proved [75]. The imidazolium liquids are among the most popular ionic liquids applied in the SILP systems, and this brings about continuous improvement in the systems in which they are employed. An example is a new system with the use of [BMIM] $\mathrm{PF}_{6}$ and pyrogenic amorphous Aerosil silica, which was applied as a catalyst for the synthesis of benzimidazole - the compound that has fungicidal properties [76].

Recently, a trend has been observed to employ transition metal complexes with chelating ligands that have reaction regioselectivity-improving properties. It is no wonder that these complexes have found application in SILPC systems. Brunig et al. used iron complexes of this type for the hydrogenation of aldehydes. The aforementioned catalytic system showed high chemoselectivity in reactions with aliphatic and aromatic aldehydes under mild reaction conditions [77]. When polymer-originated spherical active carbon (CARB) was employed as a support for the above catalytic system, conversions of substrates in analogous catalytic reactions were lower compared to the performance of the same catalytic system supported on silica despite an extension of the reaction time [78]. The utilization of new porous materials is one of the main trends observed in SILP materials. One of the recent examples is the employment of graphene oxide for this purpose, where graphene oxide served as a matrix for covalently bound ionic liquid (1- $N$-ferrocenylmethyl benzimidazole). The obtained system was applied with a very good result in the synthesis of 3,4-dihydro-2H-naphthol[2-e][1,3]oxazine-5,10-dione. The catalytic reaction in the presence of the SILP material proceeded fast and environmentally mild solvents were used [79]. On the other hand, phosphonium ionic liquid-modified silica with the addition of a palladium catalyst has been employed in the reaction of aminocarbonylation. Due to the utilization of the SILP system of this type, it was possible to conduct the reaction of double carbonylation in 
a nonpolar solvent. Moreover, the modification of the silica surface resulted in a considerable reduction in the palladium catalyst leaching from the support surface [80]. Another interesting idea seems to be the application of SILP systems to the immobilization of enzymes. The first example of the enzyme-SILP system is the immobilization of Candida Antarctica Lipase A with the use of 1-octyl-3-methylimidazolium tetrafluoroborate on the surface of a microglobule-forming monolith being a combination of cellulose and Teflon. By loading the reactor interior with the obtained SILP material, it was possible to conduct the reaction of transesterification in the continuous phase with very good results [81].

Reactions in the continuous phase are an essential aspect of the utilization of the SILP systems, particularly in the context of their application in the industry. The next step in this direction is the employment of multi-walled carbon nanotubes (MWCNTs) as supports in the SILP systems. Two kinds of MWCNT-based supports were obtained, namely with incorporated silica (for hydroformylation) or alumina (for water-gas shift reaction). To produce silica- or alumina-containing SILPC materials, ruthenium and rhodium catalysts, as well as imidazolium and phosphonium ionic liquids, were employed. In both cases, the reactions were carried out in a reactor and the isolation of products was performed with the use of membranes. Results obtained for 1-butene hydroformylation have shown that in the presence of the support consisting of MWCNT alone, the catalytic activity was higher than in the presence of the MWCNT-SiO 2 system. The reduction in the activity was a result of the calcination process that was carried out at a temperature at which MWCNTs are unstable. In the case of the water-gas shift reaction (WGSR), the conversion was higher when alumina was present in the SILP system. The reactions conducted in the presence of $\mathrm{MWCNT}-\mathrm{Al}_{2} \mathrm{O}_{3}$ were characterized by a higher selectivity. It is also worth mentioning that the application of nanotube-containing SILPs as the filling of reactors enables better control of mass and heat transfer in the conducted reactions [82]. The WGSR that produces hydrogen and carbon dioxide is of great importance for several industrial processes such as Fischer-Tropsch and Haber-Bosch syntheses. The latter are conducted at high temperatures ranging from 200 to as high as $550^{\circ} \mathrm{C}$. The employment of SILPC systems in reactions of this type permits the considerable reduction in the process temperature (to $120-160^{\circ} \mathrm{C}$ ), which is a very promising solution. Unfortunately, a serious counter-indication to the application of the SILP materials for this purpose is the poor solubility of carbon monoxide in the ionic liquids. Wolf et al. investigated the effect of the addition of metal chlorides incorporated into the Ru-SILP system on the catalytic activity for WGSR and found that the incorporation of $\mathrm{CuCl}$ into the SILP material considerably improved the catalytic activity, as evidenced by the increase in the conversion by $30 \%$ [83]. The SILP materials with an ionic liquid having properties characteristic of Brønsted acids have been employed in the process of fuel desulfurization. The ionic liquid (4-(3'-ethylimidazolium)-butanesulfonate) was subjected to protonation with the use of two heteropolyacids $\left(\mathrm{H}_{3} \mathrm{PMo}_{12} \mathrm{O}_{40}\right.$ and $\left.\mathrm{H}_{3} \mathrm{PW}_{12} \mathrm{O}_{40}\right)$ followed by immobilization on surfaces of silica and $\gamma$-alumina. The obtained SILP systems imparted stability to heteropolyanions, due to which the formed catalytic system became stable and enabled several oxidation reactions to be conducted with the use of the same portion of the catalyst [84]. On the other hand, the SILP system with Lewis acid centers appeared to be a good catalytic solution to selective hydrogenation of benzofuran derivatives. The SILP material consisting of silane-functionalized imidazolium ionic liquid and silica was subjected to impregnation with zinc chloride and also contained ruthenium nanoparticles. An essential aspect of the preparation of the above system was the introduction of the catalyst nanoparticles at the last stage of the synthesis, directly onto the anionic surface, due to which it became covalently bound to the support [85]. However, the utilization of SILP systems does not always require special preparation or modification of materials being its components. The relevant examples are popular hydrosilylation catalysts consisting of rhodium, phosphonium ionic liquids, and silica. The most active system ([ $\left.\left.\left[\mathrm{Rh}\left(\mu-\mathrm{OSiMe}_{3}\right)(\mathrm{cod})\right\}_{2}\right] /\left[\mathrm{P}_{66614}\right]\left[\mathrm{NTf}_{2}\right]-\mathrm{SiO}_{2}\right)$ enabled us to conduct as many as 20 catalytic cycles with very good yield. This made it possible to limit the amount of metal in the products, the isolation of which was also simple and less time-consuming compared to standard techniques [86]. The literature reports on the supported ionic liquid phase published in recent years indicate the application of modified supports or inorganic-organic hybrid 
materials as the solid phase in the SILP materials to reduce leaching of ionic liquid and catalyst from the system. Increasingly more often, the catalysts are also subject to modifications aimed at improving their adsorption on the SILP materials, among others, by employing chelating ligands or using metal nanoparticles. The enzyme-containing SILP systems, which are an entirely new solution to the enzymatic reactions, will certainly be developed in the near future. However, the greatest interest is seen in the SILP systems employed as solid beds in the reactors to enable reactions to be conducted in the continuous phase. In particular, the application of materials based on carbon nanotubes that enable better control of mass transfer in the catalytic systems will certainly find its reflection in further research works.

\subsection{Solid Catalyst with Ionic Liquid Layer (SCILL)}

Another way of ionic liquid application in catalysis, where the ionic liquid does not directly take part in reactions but is employed as a layer directly applied onto solid catalysts, is the so-called solid catalyst with ionic liquid layer (SCILL). Heterogeneous catalysts, despite their many advantages, are unfortunately often characterized by a lower selectivity compared to homogeneous ones. In this case, the role of IL is the modification of the surface, its homogenization, and the improvement in selectivity in some reactions, as well as the protection of the catalyst against poisoning. An appropriate selection of ionic liquid makes it possible to control the solubility of substrates and products in IL, thereby facilitating the access of desired reagents to catalytic centers and limiting the occurrence of undesired reactions. Moreover, the selection of ionic liquid in which the solubility of reactants is greater than that of the products formed enables the easy isolation of reaction products [55,87]. The essential difference between the SCILL and SILP systems consists of employing, in the SCILL materials, only heterogeneous catalysts that are covered with a thin layer of ionic liquid, whereas in the case of SILP materials, porous support is used [50]. There are two kinds of SCILLs; in the former case, a layer of the ionic liquid is placed on a solid catalyst (Figure 6a), and in the latter case, the ionic liquid covers the solid catalyst placed on an inert support (Figure 6b).

a)

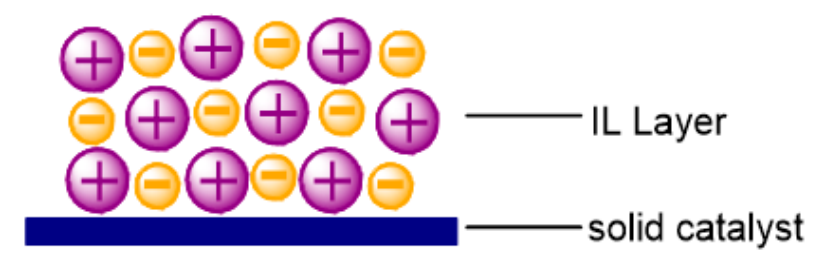

b)

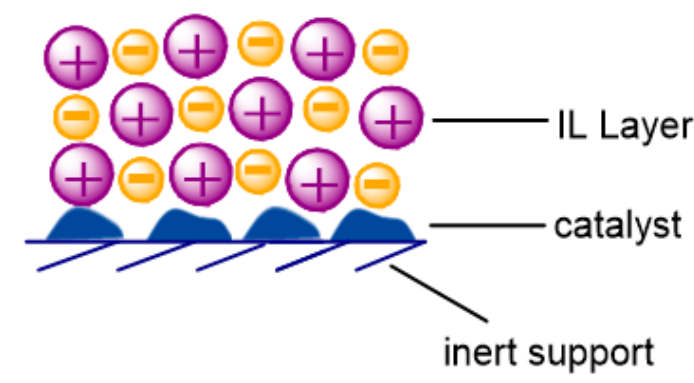

Figure 6. Two kinds of solid catalysts with ILs (SCILLs): (a) With catalytically active support; (b) with heterogeneous catalyst on an inert support.

The first reports on materials of this type were published in 2007 by Kernchen et al. [50,88,89]. They concerned the reaction of cyclooctadiene hydrogenation to cyclooctene with the use of SCILL materials based on nickel catalyst covered with ionic liquid [BMIM] $\left[\mathrm{n}-\mathrm{C}_{8} \mathrm{H}_{17} \mathrm{OSO}_{3}\right.$ ], which enabled it to achieve $70 \%$ conversion [88]. Further research widened the assortment of ionic liquids employed in the SCILL systems and proved a significant effect of the ionic liquid cation on their catalytic activity in hydrogenation reactions [90]. The latter were conducted with the use of SCILL materials, among others, for alkynes, aldehydes, and naphthalene [55]. An interesting solution for reactions of this type has been proposed by Antonels and Meijboom. In the reaction of citral hydrogenation, silica-supported nanoparticles of ruthenium catalyst with added dendrimers were employed. Then, imidazolium ionic liquids differing in anions and cations were applied onto the obtained ruthenium systems. It was 
shown that in some SCILL systems, the ionic liquid prevented catalyst poisoning due to the removal of formed $\mathrm{CO}$ from the system as a result of the competitive reaction of decarboxylation. The best catalytic results were obtained for the SCILL systems with [BMIM][NTf ${ }_{2}$ ] [91]. The catalytic properties of the SCILL systems consisting of ruthenium dendrimers (RuDEN) and different ionic liquids were compared with the RuDEN catalytic system without ionic liquids in toluene hydrogenation. All SCILL catalytic systems have shown higher activity and better selectivity than RuDEN catalysts [92]. In the case of the reaction of 1,3-butadiene hydrogenation, the application of commercially available nickel catalyst and ionic liquid ([BMIM] $\left.\left[\mathrm{BF}_{4}\right]\right)$ made it possible to obtain butene with the yield of 95\% [93]. Modified SCILL systems containing acidic ionic liquids and palladium catalyst supported on active carbon were employed for the hydrogenation of arenes, which resulted in an increase in the reaction yield, and in the case of toluene hydrogenation, it was possible to reduce the reaction temperature to $40^{\circ} \mathrm{C}$ [94]. Palladium-containing SCILL systems were used to selectively obtain butene, and a $99 \%$ conversion of the substrate was achieved [95].

The ionic liquid in the SCILL system also appeared to be useful in the development of an active and selective hydrogenation catalyst, one of the components of which was the discarded fluid cracking catalyst DF3C. The latter was used as a support in the catalytic system containing $10 \mathrm{wt} \%$ nickel and ionic liquid (1-ethanol-3-methylimidazolium tetrafluoroborate) [96]. The system was employed for the hydrogenation of $\alpha$-pinene to cis-pinane and enabled the maintaining of the conversion of $\alpha$-pinene on the level of about $99 \%$ during 13 catalytic cycles, after which the performance of the catalyst deteriorated due to leaching of the ionic liquid. Both the activity and selectivity of the SCILL system depended on the amount of the IL (or in other words, on the thickness of the IL layer). At the IL loading exceeding $10 \mathrm{wt} \%$, the selectivity to cis-pinane was over $98 \%$; however, at the loading of $5 \mathrm{wt} \%$, it had fallen to about $90 \%$. Such utilization of the waste industrial catalyst as that described for the spent cracking catalyst DF3C is useful both from the viewpoint of the economy and from that of environmental protection.

The reaction of ethene hydrogenation was studied by Bauer at al. [97] in the presence of the Pd-SCILL system, who found that the above alkene reacted with the layer of ionic liquid 1-ethyl-3-methylimidazolium ethylsulfate, which resulted in the formation of a new ionic liquid 1,2-diethyl-3-methylimidazolium ethylsulfate. Their study opens the way to the synthesis of new ionic liquids or modification of their properties on the surface of the SCILL materials [98].

Not only have the SCILL systems found applications in hydrogenation reactions, but they have also been employed in the reactions of catalytic oxidation, isomerization, and Knoevenagel condensation. The selective oxidation of benzyl alcohol with air was catalyzed by platinum ( $5 \mathrm{wt} \%$ ) supported on cryptomelane $\left(\mathrm{KMn}_{8} \mathrm{O}_{16}\right)$ covered with imidazolium or pyrrolidinium ionic liquid-[BMIN][NTf $\left.\mathrm{N}_{2}\right]$ or [BMPy] $\left[\mathrm{NTf}_{2}\right]$, respectively. In the presence of the former IL, the conversion of benzyl alcohol on the above catalytic system was $80 \%$ and the selectivity for aldehyde was $82 \%$ [99]. The oxidative coupling of aromatic thiols to disulfides in the presence of homogeneous catalysts has several shortcomings, whereas the application of heterogeneous catalytic SCILL systems to the aforementioned reactions makes it possible to limit the amount of metal in the product, to easily isolate the catalyst from the post-reaction mixture and to prevent catalyst poisoning. To take the above advantages, ruthenium- and platinum-containing SCILL systems with ionic liquids [BMIM][NTf $f_{2}$, [EMIM][NTf $f_{2}$, and $[\mathrm{BMPyr}]\left[\mathrm{NTf}_{2}\right]$ were applied in the mentioned reactions of thiols under mild conditions to result in satisfactory yields in three subsequent catalytic cycles [100]. The success of skeletal isomerization of chemical compounds largely depends on the catalyst acidity. This is why the employment of the SCILL systems with acidic ionic liquids in reactions of this type is an interesting idea. The platinum-containing SCILL system with the ionic liquid being a strong Lewis acid $\left(\left[\mathrm{C}_{4} \mathrm{C}_{1} \mathrm{IM}\right] \mathrm{Cl} / \mathrm{AlCl}_{3}\right)$ was applied in n-octane isomerization [101]. In one of the recent papers on the SCILL systems, their application in the Knoevenagel reaction was reported. The system employed in the above reaction made it possible to effectively conduct condensation of aldehydes with cyanoacetate and malononitrile in aqueous 
medium at room temperature. The catalytic system with basic properties enabled the good conversion of substrates in five subsequent catalytic cycles [102].

In the literature on the SCILL materials visible is an increase in reports on their applications in reactions other than hydrogenation. The diversity of catalytic reactions with their participation makes researchers introduce improvements in the SCILLs structure. In addition to the syntheses of specialty ionic liquids and the modification of catalyst structure, increasingly more research is often carried out on the formation of bifunctional SCILL systems. Their stability and durability, as well as applicational potential in many, often complicated, organic syntheses, will certainly be developed in further research.

\subsection{Porous Ionic Liquids}

The term porous ionic liquids, i.e., liquid materials that are characterized by permanent microporosity, was introduced in 2007 by James et al. [103]. The porous ionic liquids can be classified into three types. The first of them is a pure molecular unit with empty cavities that are rigid (which prevents them from collapsing) and their shape renders the intermolecular self-filling of pores of the liquid impossible. The second type, so-called liquids of "empty host" type, includes ionic liquids that are dissolved in the solvents with a steric hindrance. In addition, these liquids are characterized by high rigidity and permanence of pores, which do not collapse even when unfilled. It is also essential that solvent molecules cannot fill voids in the porous liquid structure. The third type is a dispersion of solid porous materials in the liquid matrix whose molecules are too large to enter the pores of the solid. These materials form porous phases that contain ionic liquids and additionally solid particles of microporous materials that make a skeleton of the whole system. Porous ionic liquids have properties characteristic of both ionic liquids and porous materials due to which they are characterized by large surface area, very good mechanical strength, and the capability of modifying their structure. Moreover, the presence of easy-to-exchange ions in their pores causes a change in the chemical properties of the material. It is also worth mentioning that porous ionic liquids are characterized by high polarization and high ionic density [104].

One of the methods of the preparation of porous ionic liquids is synthesis with the use of so-called templates. There exist methods based on the use of soft and hard templates. Generally, these methods consist of conducting in situ polymerization of ionic liquid monomers or the copolymerization of ionic liquid with another monomer [104-106]. An example of synthesis with the use of hard templates, which make it possible to obtain materials with a specified pore size, is the employment of colloidal silica dispersed in an ionic liquid monomer. After crosslinking followed by removal of the template (silica) from the formed structure, a mesoporous ionic liquid was obtained [105]. It is worth pointing out that the method employing hard templates enables the obtaining of meso- and macroporous materials [107], whereas that based on the use of soft templates results in the production of mesoporous materials and consists of the utilization of surfactants and formation of micelles [107,108].

Porous ionic liquids can also be obtained without the application of templates. An example of such a synthesis is the radical copolymerization of divinylbenzene and vinyl group-containing imidazolium ionic liquid [109]. In other literature reports, the possibility of obtaining porous ionic liquids via complexation of poly(ionic liquids) with the use of acids $[110,111]$ was presented. The methods of producing porous ionic liquids have continually improved and modified. However, irrespective of the preparation method, these materials make a construction that can be successfully applied in heterogeneous catalysis. One of the first examples of the application of ionic liquids as catalysts is the Suzuki-Miyaura cross-coupling reaction, which employs palladium nanoparticles supported on a porous ionic polymer (PIP). First, the ionic liquid was obtained through the reaction of 1-vinylimidazole with bromoacetic acid, followed by its employment in the radical polymerization with vinylbenzene in the presence of azobisisobutyronitrile (AIBN) and ethanol. The system Pd-PIP was prepared in situ through the impregnation in an ethanolic solution of $\mathrm{Pd}(\mathrm{OAc})_{2}$. The obtained catalytic material appeared to be ideally suited for conducting coupling reactions with aryl bromides and chlorides and phenylboronic acid. Moreover, it was possible to recycle and reuse it in subsequent reactions. 
Due to the presence of the carboxyl group and carbene structure, palladium nanoparticles were very well-stabilized and did not aggregate [112]. On the other hand, the heteropolyanion-containing copolymer was used in the reaction of benzene hydroxylation with hydrogen peroxide. A hybrid porous catalyst was produced by polymerization of ionic liquid (3-n-butyl-1-vinylimidazolium bromide ([VBIM][Br] )) with divinylbenzene (DVB) in the presence of AIBN. The copolymer obtained in this way was subjected to impregnation with heteropolyacid $-\mathrm{H}_{5} \mathrm{PMo}_{10} \mathrm{~V}_{2} \mathrm{O}_{40}$, which resulted in the exchange of anions and formation of a porous cross-linked copolymer based on heteropolyacid (HPA) (Scheme 1). The produced catalytic system showed very good catalytic activity for hydroxylation, due to, among others, its large surface area and suitable pore size. Its isolation from the post-reaction mixture was easy, which made it possible to reuse it [113].

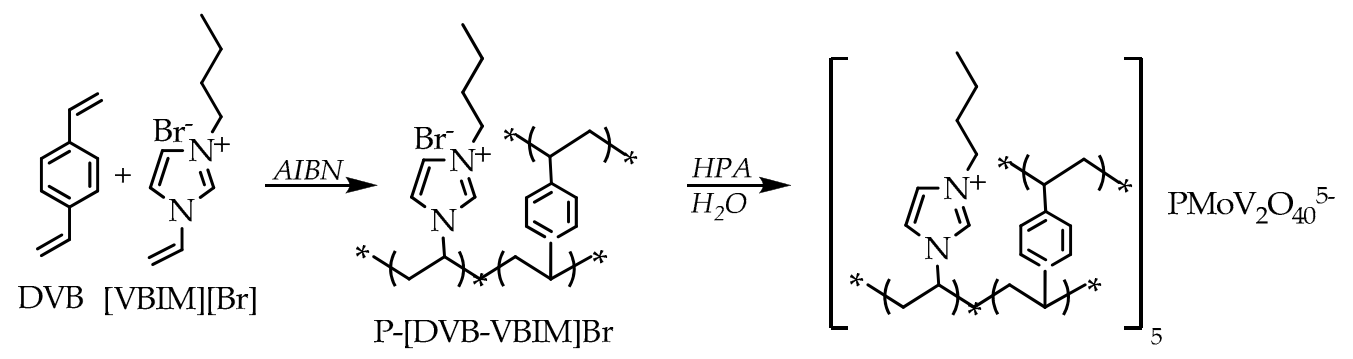

Scheme 1. Synthesis of the porous HPA-based cross-linked polymeric IL catalyst $\mathrm{P}-[\mathrm{DVB}-\mathrm{VBIM}]_{5} \mathrm{PMoV}_{2}$ [113].

Another example of synthesis without a template is the polymerization of 3-cyanomethyl-1-vinylimidazolium-based ionic liquid with polyacrylic acid. The resulting polymer served as a support for copper chloride, and the catalytic system produced in this way has been employed in the oxidation of cyclic compounds. The reaction was carried out in mild conditions and was characterized by very good yield and selectivity [114]. An interesting example of synthesis with the use of a soft template was the free-radical polymerization of ionic liquid 1-allyl-3-vinylimidazolium with the participation of triblock copolymer P123 (copolymer of ethylene oxide and propylene oxide). The exchange of the chloride anion for phosphotungstic heteropolyanion resulted in a very active catalyst for epoxidation of cis-cyclooctene with hydrogen peroxide [115]. A very similar procedure with the use of the same template P123 was applied in the copolymerization of 1-butyl-3-vinylimidazolium bromide and divinylbenzene followed by ion exchange for phosphotungstic heteropolyanion. The obtained material was employed in the alkylation of styrene and o-xylene [116]. Porous ternary materials, obtained by polymerization of divinylbenzene, 1-vinylimidazole, and 1-vinyl-3-butylimidazolium bromide, were applied in the same reaction. The systems of this type were characterized by a greater number of acid groups and active centers on their surface than their binary analogs. Additionally, the presence of micro- and mesopores in the structure of the porous ternary polymer increased the possibility of contact between reagents, which resulted in the high conversion of substrates (99\%) [117]. The high activity of porous ionic liquids as catalytic systems can be achieved not only by the formation of certain structures but also by the generation of acid-base properties. An example of basic, hydrophobic, and mesoporous poly (ionic liquid) is the material produced by copolymerization of 1-aminoethyl-3-vinylimidazole bromide with divinylbenzene followed by the exchange of a bromide anion for a hydroxyl one. This copolymer has been employed in the solvent-free condensation of benzaldehyde with ethyl cyanoacetate (Knoevenagel reaction), and its catalytic activity significantly surpassed that of commercially available strongly basic resins, as well as $\mathrm{NaOH}$, which are known for their activity for the above reaction [118]. On the other hand, a nanoporous poly (ionic liquid) with a strong acidic character was produced by copolymerization of divinylbenzene with the ionic liquid containing 1-vinylimidazolium or vinylpyridinium cation and $\mathrm{SO}_{3} \mathrm{CF}_{3}$ or $\mathrm{SO}_{3} \mathrm{H}$ anions. The synthesized catalytic material permitted the conduction of the hydration of alkynes to ketones, and its effectiveness was higher than that of 
commercially available acids commonly used in reactions of this type. Moreover, this material was easy to regenerate, which enabled its employment in subsequent reactions [119].

In recent years, a strong interest has been observed in the application of porous ionic liquids to capturing $\mathrm{CO}_{2}$ and its cycloaddition to cyclic hydrocarbons and epoxides [120]. An example of such a material is poly (divinylbenzeno-1-allyl-tetramethylguanidinium) bromide, which enables the achieving of a conversion higher than that obtained when using standard reaction systems without porous materials. In addition, the materials composed of ionic liquids and metal-organic frameworks (IL-MOF) have found application in the reactions of $\mathrm{CO}_{2}$ cycloaddition. The use of materials of this type in the latter reactions has been recently reviewed by Wang et al. [121]. The interest in IL-MOFs has not abated, due to their structure, which captures $\mathrm{CO}_{2}$ very effectively. Then, the latter can be utilized in the aforementioned reaction. The ordered structure, very good adsorption properties (caused, among others, by the large surface area), and metal-ligand interactions are the reason for the stability and very good catalytic properties of these materials [121,122]. The MOF materials are heterogeneous systems with very good catalytic stability. They can show, if appropriately tailored, the selectivity toward reagents of a specific size. The catalytic performance of these porous materials can be additionally upgraded by their functionalization with ionic liquids. To this end, the method of ionic liquid encapsulation within the MOF structure is employed most often. It has been shown that the ionic liquid enters the pores of the metallic structure where the metal forms a coordinate bond with a functional group (e.g., amino group) of the ionic liquid. An important aspect of the above synthesis of IL-MOF materials is the solvent choice in such a way that no affinity occurs between the solvent and the porous surface, and at the same time, the ionic liquid coordination is not restricted [107,123-125]. A relatively new method of the preparation of IL-MOF materials, developed by Khan et al. [126], is the so-called "ship-in-bottle" technique. To this purpose, they used the porous structure of chromium terephthalate, which played the role of host (bottle), inside which the ionic liquid (ship) has been synthesized. The substance of the method is that the dimensions of the ionic liquid synthesized inside the MOF host are greater than the host pores, which makes its removal impossible. The preparation of the ionic liquid occurs through the penetration of the IL precursors ( $N$-methylimidazole and 1-bromobutane) via pores to the interior of the host structure, where the synthesis takes place. Due to the ionic liquid trapping inside the MOF structure, the problem of its eluting has been eliminated. The IL-MOF systems can also be obtained by utilizing capillary forces $[122,127]$. Examples of the application of the IL-MOF materials were presented in the review paper by Fujie and Kitagawa [125]. Recent reports on the IL-MOFs concern the systems containing more than one metal. The multi-metallic MOFs, as they were named by Sun at al. [128], are a real challenge. Just joining together several catalytically active systems into an integral whole that will be characterized by an ordered structure creates many problems. That is why the mechanochemical synthesis has been applied to prepare the new catalytic material. It has been shown that the obtained catalytic system, containing the binary MOF system in its structure, is characterized by the far better conversion of substrates in the cycloaddition of epoxy compounds to carbon dioxide than its single analog. The proposed method of the preparation of the IL-MOF materials consisting of two metals (and maybe, in the future, even several ones) opens the way to interesting new applications of the systems of this type. In addition, another porous organometallic structure named ZIF-8, which contains zinc ions and 2-methylimidazolium ligands, is willingly used in ionic liquid-containing systems. The addition of as small an amount as 5\% of ZIF-8 material to the ionic liquid considerably improved the adsorption ability compared to the ionic liquid alone [129]. Many attempts at obtaining IL-MOF materials with just this porous structure (also in the form of colloidal solutions with permanent porosity) have confirmed their very good performance in the processes of the low-pressure separation of gases [130] and adsorption of gases in the liquid systems [131].

Porous ionic liquids provide many application possibilities. The recent synthesis of porous ionic liquids in the form of tetrahedral coordination cages proved the possibility of designing these materials in the way that enables them to fulfill specified functions [132]. A wide variety of compounds, e.g., alcohols (butanol, propanol), trichlorofluoromethane, dichlorodifluoromethane, and 
chlorotrifluoromethane, were adsorbed in the pores of these materials. In the future, these materials can serve for selective isolation of particular components from mixtures (e.g., by extraction), but their employment in catalytic reactions, e.g., for picking up by-products, is conceivable.

The ionic porous materials were introduced relatively recently; therefore, their increased applicational development is expected in the near future. The observation of the current research trends in the field of porous ionic liquids suggests the development of new copolymeric materials consisting of more than two monomers, as well as multimetallic IL-MOFs.

\section{Conclusions}

The application of ionic liquids in different fields, including catalysis, has not abated. Through the appropriate choice of new synthesis methods and the employment of renewable and biodegradable raw materials, an increasingly greater group of derivatives is being considered safe and environmentally friendly. The role of ionic liquids in catalysis is very diversified because they can be solvents in the catalytic processes, immobilizing agents for homogeneous catalysts, components of catalysts (e.g., ligands in a complex), as well as actual catalysts [5,24-27,33,47-50]. In the case of catalysis, ionic liquids make it possible to conduct reactions with higher selectivities and yields; however, their most important asset is easy catalyst isolation from the catalytic mixture. That is why we intended to present in this mini-review several variants of heterogeneous catalysts prepared with the participation of ionic liquids. We have restricted them to three groups of such catalysts, namely, supported ionic liquid phase catalyst (SILPC), solid catalyst with ionic liquid layers (SCILL), and porous ionic liquids. However, there are considerably more ionic liquid-containing heterogeneous systems that were not presented here, because of the article volume limitations. For instance, we left out nanocatalysis (in a broad sense) with the participation of dispersed metal nanoparticles stabilized by ionic liquids [133,134], ionosilicas [135,136], and poly(ionic liquids) $[107,137]$, which can be modifying agents for polymers, copolymers, as well as play the role of catalyst in polymerization processes. Moreover, they can take part in metal-organic frameworks (MOFs) that were only very superficially mentioned when presenting porous ionic liquids $[127,138]$, although they certainly deserve more attention. In many cases, metal-containing ionic liquids (metallate ionic liquids) also form heterogeneous systems and are successfully applied in catalysis $[139,140]$. Therefore, the three variants of heterogeneous systems presented in this article are only a modest, albeit one of the most common, examples of systems of this type. Undoubtedly, the SILPCs belong to the most popular and increasingly more frequently employed catalytic systems [55-58]. One of the first and best-explored processes conducted with their participation is hydroformylation [60]. However, there are currently many other SILPC-catalyzed processes [64] such as oxidation, coupling (reactions of Heck, Suzuki, etc.), hydroamination, and isomerization of hydrocarbons. Another heterogeneous system presented in this paper is SCILL, which takes advantage of the properties of ionic liquid that covers a solid catalyst with a thin layer to facilitate better access of reagents to the catalyst and thereby improves the process selectivity and yield [88]. The most prevalent process carried out with the participation of SCILL is hydrogenation, albeit recent reports appeared on the processes of oxidation, isomerization, and Knoevenagel condensation [99-102]. Finally, the third type of heterogeneous systems presented in this paper is porous ionic liquids [104,107], which also include metal-organic frameworks formed with the participation of ionic liquids [129]. The systems of this type, due to their structure and high catalytic stability, has attracted increasingly more attention [125]. Among the most interesting directions of their application is the capture of $\mathrm{CO}_{2}$ and its cycloaddition to cyclic hydrocarbons and epoxides [120]. However, the possibilities of their applications are much wider both in chemical and enzymatic catalysis [141]. The above-presented examples of the applications of the systems are only selected ones and certainly do not exhaust all their possibilities. Our goal was to indicate their large application potential that will soon be increasingly more frequently utilized in many chemical processes. In all the above systems, the problems occurring in the case of catalysis in homogeneous systems have been eliminated. First, there is no problem with the isolation of catalyst, which is heterogeneous. Second, because ionic liquid covers the supports with 
a thin layer, a small amount of IL is needed, which results in a considerable cost reduction (despite the high price of ionic liquids). In addition, due to the thinness of the layer, the viscosity of IL does not influence the course of the process and the mass transfer does not create a problem. Thirdly, due to the form of catalyst, continuous flow reactors can be employed, which also influences the process economics. This is why a considerable development of heterogeneous catalysts of this type and their application in many processes can be expected in the future. Therefore, ionic liquids proved again their capability of evolving and adapting to various technological, economic, and environmental regimes.

Author Contributions: Conceptualization, H.M.; literature search, O.B. and A.S.; writing-review and editing, O.B., A.S., I.D. and H.M.; supervision, H.M.; funding acquisition, H.M. and O.B. All authors have read and agreed to the published version of the manuscript.

Funding: This research was funded by the National Science Centre (Poland), project OPUS grant number UMO-2014/15/B/ST5/04257 and project PRELUDIUM grant number UMO-2019/35/N/ST4/00494.

Conflicts of Interest: The authors declare no conflict of interest.

\section{References}

1. The New Material. The Twenty Most Potential New Materials in the Future. 2014. Available online: https://new.qq.com/omn/20191105/20191105A098C000.html (accessed on 21 October 2020).

2. ISI Web of Science Search. Available online: https://clarivate.com/webofsciencegroup/solutions/web-ofscience/ (accessed on 21 October 2020).

3. Wasserscheid, P.; Welton, T. Ionic Liquids in Synthesis; Wiley-VCH: Weinheim, Germany, 2003.

4. Adams, D.J.; Dyson, P.J.; Tavener, S.J. Chemistry in Alternative Reaction Media; Wiley: Chichester, UK, 2004.

5. Vekariya, R.L. A review of ionic liquids: Applications towards catalytic transfromations. J. Mol. Liq. 2017, 227, 44-60. [CrossRef]

6. Javed, F.; Ullah, F.; Zakaria, M.R.; Akil, H.M. An approach to classification and hi-tech applications of room-temperature ionic liquids (RTILs): A review. J. Mol. Liq. 2018, 271, 403-420. [CrossRef]

7. Singh, S.K.; Savoy, A.W. Ionic liquids synthesis and applications: An overview. J. Mol. Liq. 2020, $297,112038$. [CrossRef]

8. Walden, P. Über die Molekulargrösse und elektrische Leitfähigkeit einiger geschmolzener Salze. Bull. Acad. Imp. Sci. 1914, 8, 405-422.

9. Hurley, F.H.; Weir, T.P. Electrodeposition of metals from fused quaternary ammonium salts. J. Electrochem. Soc. 1951, 98, 203-206. [CrossRef]

10. Wilkes, J.S.; Zaworotko, M.J. Air and water stable 1-ethyl-3-methylimidazolium based ionic liquids. J. Chem. Soc. Chem. Commun. 1992, 965-967. [CrossRef]

11. Wierzbicki, A.; Davis, J.H., Jr. Envisioning the second generation of ionic liquid technology: Design and synthesis of Task-specific Ionic Liquids (TSILs). In Proceedings of the Symposium on Advances in Solvent Selection and Substitution for Extraction, Atlanta, Georgia, 5-9 March 2000; AIChE: New York, NY, USA, 2000.

12. Welton, T. Ionic Liquids: A brief history. Biophys. Rev. 2018, 10, 691-706. [CrossRef]

13. Earle, M.J.; Esperanca, J.M.S.S.; Gilea, M.A.; Lopes, J.N.C.; Rebelo, L.P.N.; Magee, J.W.; Seddon, K.R.; Widegren, J.A. The distillation and volatility of ionic liquids. Nature 2006, 439, 831-834. [CrossRef]

14. Clark, J.H.; Tavener, S.J. Alternative solvents: Shades of green. Org. Proc. Res. Dev. 2007, 11, 149-155. [CrossRef]

15. Jessop, P.G. Searching for green solvents. Green Chem. 2011, 13, 1391-1398. [CrossRef]

16. Cevasco, G.; Chiappe, C. Are ionic liquids a proper solution to current environmental challenges? Green Chem. 2014, 16, 2375-2385. [CrossRef]

17. Frade, R.F.; Alonso, C.A. Impact of Ionic Liquids in environment and humans: An overview. Hum. Exp. Toxicol. 2010, 29, 1038-1054. [CrossRef] [PubMed]

18. Kunz, W.; Hackl, K. The hype with ionic liquids as solvents. Chem. Phys. Lett. 2016, 661, 6-12. [CrossRef]

19. Anastas, P. (Ed.) Green Solvents; Wiley-VCH: Weinheim, Germany, 2010.

20. Ameta, G.; Pathak, A.K.; Ameta, C.; Punjabi, P.B. Sonochemical synthesis and imidazolium based ionic liquids: A green pathway. J. Mol. Liq. 2015, 211, 934-937. [CrossRef] 
21. Naeimi, H.; Nazifi, Z.S. A facile one-pot ultrasound assisted synthesis of 1,8-dioxooctahydroxanthene derivatives catalysed by Bronsted acidic ionic liquid (BAIL) under green conditions. J. Ind. Eng. Chem. 2014, 20, 1043-1049. [CrossRef]

22. Martinez-Palou, R. Microwave-assisted synthesis using ionic liquids. Mol. Divers. 2010, 14, 3-25. [CrossRef]

23. Itoh, T.; Koo, Y.-M. (Eds.) Application of Ionic Liquids in Biotechnology; Springer: Cham, Switzerland, 2019.

24. Ozokwelu, D.; Zhang, S.; Okafor, O.C.; Cheng, W.; Litombe, N. Novel Catalytic and Separation Processes Based on Ionic Liquids; Elsevier: Amsterdam, The Netherlands, 2017.

25. Saha, B.; Fan, M.; Wang, J. (Eds.) Sustainable Catalytic Process; Elsevier: Amsterdam, The Netherlands, 2015.

26. Dupont, J.; Itoh, T.; Lozano, P.; Malhotra, S.V. (Eds.) Environmentally Friendly Syntheses Using Ionic Liquids; CRC Press: New York, NY, USA, 2015.

27. Lozano, P. Sustainable Catalysis in Ionic Liquids; CRC Press: New York, NY, USA, 2019.

28. Alvarez, M.S.; Zhang, Y. Sketching neoteric solvents for boosting drugs bioavailability. J. Controll. Release 2019, 311, 225-232. [CrossRef]

29. Villa, R.; Alvarez, E.; Porcar, R.; Garcia-Verdugo, E.; Luis, S.V.; Lozano, P. Ionic Liquids as an enabling tool to integrate reaction and separation processes. Green Chem. 2019, 21, 6527-6544. [CrossRef]

30. Gaida, B.; Brzęczek-Szafran, A. Insights into the Properties and Potential Applications of Renewable Carbohydrate-Based Ionic Liquids: A Review. Molecules 2020, 25, 3285. [CrossRef]

31. Gomes, J.M.; Silva, S.S.; Reis, R.L. Biocompatible ionic liquids: Fundamental behaviors and applications. Chem. Soc. Rev. 2019, 48, 4317-4335. [CrossRef]

32. Welton, T. Solvents and sustainable chemistry. Proc. R. Soc. A Mat. 2015, 471, 50502. [CrossRef] [PubMed]

33. Olivier-Bourbigou, H.; Magna, L.; Morvan, D. Ionic Liquids and Catalysis: Recent progress from knowledge to applications. Appl. Catal. A 2010, 373,1-56. [CrossRef]

34. Hajipour, A.R.; Rafiee, F. Recent progress in ionic liquids and their applications in organic synthesis. Org. Prep. Proced. Int. 2015, 47, 249-308. [CrossRef]

35. Sahin, S. Tailor-designed deep eutectic liquids as a sustainable extraction media: An alternative to ionic liquids. J. Pharm. Biomed. Anal. 2019, 174, 324-329. [CrossRef]

36. Kalhor, P.; Ghandi, K. Deep Eutectic Solvents for Pretreatment, Extraction and Catalysis of Biomas and Food Waste. Molecules 2019, 24, 4012. [CrossRef]

37. Unli, A.E.; Arikaya, A.; Takac, S. Use of deep eutectic solvents as catalyst: A mini-review. Green Process Synth. 2019, 8, 355-372. [CrossRef]

38. Eyckens, D.J.; Henderson, L.C. A review of Solvate Ionic liquids: Physical Parameters and Synthetic Applications. Front. Chem. 2019, 7, 263. [CrossRef]

39. Salar-García, M.J.; Ortiz-Martínez, V.M.; Hernández-Fernández, F.J.; de los Ríos, A.P.; Quesada-Medina, J. Ionic liquid technology to recover volatile organic compounds (VOCs). J. Hazard. Mater. 2017, 321, 484-499. [CrossRef]

40. Watanabe, M.; Thomas, M.L.; Zhang, S.G.; Ueno, K.; Yasuda, T.; Dokko, K. Application of ionic liquids to energy storage and conversion materials and devices. Chem. Rev. 2017, 117, 7190-7239. [CrossRef]

41. Balducci, A. Ionic liquids in Lithium-ion batteries. Top. Curr. Chem. 2017, 375, 20. [CrossRef]

42. Itoh, T. Ionic liquids as tool to improve enzymatic organic synthesis. Chem. Rev. 2017, 117, 10567-10607. [CrossRef]

43. Ventura, S.P.M.; Silva, F.A.E.; Quental, M.V.; Monda, D.; Freire, M.G.; Coutinho, J.A.P. Ionic-liquid-mediated extraction and separation processes for bioactive compounds: Past, present, and future trends. Chem. Rev. 2017, 117, 6984-7052. [CrossRef] [PubMed]

44. Kristfikova, D.; Modrocka, V.; Meciarova, M.; Sebsta, R. Green Asymetric Organocatalysis. ChemSusChem 2020, 13, 2828-2858. [CrossRef] [PubMed]

45. Egorova, K.S.; Gordeev, E.G.; Ananikov, V.P. Biological activity of ionic liquids and their application in pharmaceutics and medicine. Chem. Rev. 2017, 117, 7132-7189. [CrossRef] [PubMed]

46. Nancarrow, P.; Mohammed, H. Ionic liquids in space technology-Current and future trends. Chembioeng Rev. 2017, 4, 106-119. [CrossRef]

47. Dyson, P.J.; Geldbach, T.J. Metal Catalysed Reactions in Ionic Liquids; Springer: Dordrecht, The Netherlands, 2005.

48. Dupont, J.; Kollar, L. Ionic Liquids (ILs) in Organometallic Catalysis; Springer: Dordrecht, The Netherlands, 2015.

49. Hardacre, C.; Parvulescu, V. Catalysis in Ionic Liquids. In Catalysts Synthesis to Applications; RS: Cambridge, UK, 2014. 
50. Domingez de Maria, P. (Ed.) Ionic Liquids in Biotransformations and Organocatalysis. Solvent and Beyond; John Wiley\&Sons, Inc.: Hoboken, NJ, USA, 2012.

51. Stevens, J.C.; Shi, J. Biocatalysis in ionic liquids for lignin valorization: Opportunities and recent developments. Biotech. Adv. 2019, 37, 107418. [CrossRef]

52. Quiroz, N.R.; Norton, A.M.; Nguyen, H.; Vasileiadou, E.; Vlachos, D.G. Homogeneous metal salt solutions for biomass upgrading and other select organic reactions. ACS Catal. 2019, 9, 9923-9952. [CrossRef]

53. Hejazifar, M.; Lanaridi, O.; Bica-Schroder, K. Ionic liquid based microemulsions: A review. J. Mol. Liq. 2020, 303, 112264. [CrossRef]

54. Qiao, Y.; Ma, W.; Theyssen, N.; Chen, C.; Hou, Z. Temperature-responsive ionic liquids: Fundamental behaviors and catalytic applications. Chem. Rev. 2017, 117, 6881-6928. [CrossRef]

55. Fehrmann, R.; Riisager, A.; Haumann, M. Supported Ionic Liquids. Fundamentals and Applications; Wiley-VCH: Weinheim, Germany, 2014.

56. Gu, Y.; Li, G. Ionic liquids-based catalysis with solids. State of the art. Adv. Synth. Catal. 2009, 351, 817-847. [CrossRef]

57. Kaur, P.; Chopra, H. Recent Advances of Supported Ionic Liquids. Curr. Org. Chem. 2019, 23, $2881-2915$. [CrossRef]

58. Feher, C.; Papp, M.; Urban, B.; Skoda-Foldes, R. Catalytic Applications of Supported Ionic Liquid Phases. In Advances in Asymmetric Autocatalysis and Related Topics; Academic Press: London, UK, 2017.

59. Kuhmann, E.; Haumann, M.; Jess, A.; Seeberger, A.; Wasserscheid, P. Ionic liquids in refinery desulfurization: Comparison between biphasic and supported ionic liquid phase suspension processes. ChemSusChem 2009, 2, 969-977. [CrossRef] [PubMed]

60. Marinkovic, J.M.; Riisager, A.; Franke, R.; Wasserscheid, P.; Haumann, M. Fifteen years of Supported Ionic Liquid Phase-Catalysed hydroformylation: Material and process developments. Ind. Eng. Chem. Res. 2019, 58, 2409-2420. [CrossRef]

61. Mehnert, C.P.; Cook, R.A.; Dispenziere, N.C.; Afeworki, M. Supported Ionic Liquid Catalysis-A New Concept for Homogeneous Hydroformylation Catalysis. J. Am. Chem. Soc. 2002, 124, 12932-12933. [CrossRef]

62. Hintermair, U.; Gong, Z.; Serbanovic, A.; Muldoon, M.J.; Santini, C.C.; Cole-Hamilton, D.J. Continuous flow hydroformylation using Supported Ionic Liquid Phase catalysts with carbon dioxide as a carrier. Dlton Trans. 2010, 39, 8501-8510. [CrossRef]

63. Illner, M.; Mulller, D.; Esche, E.; Pogrzeba, T.; Schmidt, M.; Schomacker, R.; Wony, G.; Repke, J.U. Hydroformylation in microemulsions: Proof of concept in a miniplant. Ind. Eng. Chem. Res. 2016, 55, 8616-8626. [CrossRef]

64. Romanovsky, B.V.; Tarhanova, I.G. Supported ionic liquids in catalysis. Russ. Chem. Rev. 2017, 86, 444-458. [CrossRef]

65. Li, M.; Zhang, M.; Wei, A.; Zhus, W.; Xun, S.; Li, Y.; Li, H.; Li, H. Facile synthesis of amphiphilic polyoxometalate-based ionic liquid supported silica induced efficient performance in oxidative desulfurization. J. Mol. Catal. A Chem. 2015, 406, 23-30. [CrossRef]

66. Navalon, S.; Alvaro, M.; Garcia, H. Heterogeneous Fenton catalysts based on clays, silicas and zeolites. Appl. Catal. B. 2010, 99, 1-26. [CrossRef]

67. Kim, D.W.; Chi, D.Y. Polymer-Supported Ionic Liquids: Imidazolium Salts as Catalysts for Nucleophilic Substitution Reactions Including Fluorinations. Angew. Chem. Int. Ed. 2004, 43, 483-485. [CrossRef]

68. Kim, D.W.; Hong, D.J.; Jang, K.S.; Chi, D.Y. Structural Modification of Polymer-Supported Ionic Liquids as Catalysts for Nucleophilic Substitution Reactions Including Fluorination. Adv. Synth. Catal. 2006, 348, 1719-1727. [CrossRef]

69. Termirbulatova, M.G.; Moskovskaya, I.F.; Romanovsky, B.V.; Yatsenko, A.V. MCM-41 mesoporous molecular sieves modified with a base or a palladium-containing ionic liquid as catalysts for certain organic synthesis reactions. Petrol. Chem. 2009, 49, 7-10. [CrossRef]

70. Trilla, M.; Borja, G.; Pleixats, R.; Man, M.W.C.; Bied, C.; Moreau, J.J.E. Recoverable Palladium Catalysts for Suzuki-Miyaura Cross- Coupling Reactions Based on Organic-Inorganic Hybrid Silica Materials Containing Imidazolium and Dihydroimidazolium Salts. Adv. Synth. Catal. 2008, 350, 2566-2574. [CrossRef]

71. Isaeva, V.I.; Prokudina, N.I.; Kozlova, L.M.; Kustov, L.M.; Glukhov, L.M.; Tarasov, D.L.; Beletskaya, I.P. Hydroamination of phenylacetylene in the presence of gold-containing catalytic systems supported on carriers modified by ionic liquids. Russ. Chem. Bull. Int. Ed. 2015, 64, 2811-2815. [CrossRef] 
72. Sigeev, A.S.; Beletskaya, I.P.; Petrovskii, P.V.; Peregudov, A.S. Cu(I)/Cu(II)/TMEDA, new effective available catalyst of sandmeyer reaction. Russ. J. Org. Chem. 2012, 48, 1055-1058. [CrossRef]

73. Zavalinskaya, I.S.; Malikov, I.V.; Yas'yan, Y.P. Conversion of Straight-Run Gasoline Fraction on Combined Zeolite-Containing Catalysts. Chem. Technol. Fuels Oils 2015, 51, 154-159. [CrossRef]

74. More, S.; Jadhav, S.; Salunkhe, R.; Kumbhar, A. Palladium supported ionic liquid phase catalyst (Pd@SIPL-PS) for room temperature Suzuki-Miyaura cross-coupling reaction. Mol. Catal. 2017, 442, 126-132. [CrossRef]

75. Li, Y.; Dong, Y.; Li, W.; Han, Y.; Zhang, J. Impovement of imidazolium-based ionic liquids on the activity of ruthenium catalyst for acetylene hydrochlorination. Mol. Catal. 2017, 443, 220-227. [CrossRef]

76. Sonawane, B.D.; Rashinkar, G.S.; Sonawane, K.D.; Dhanavade, M.J.; Sonawane, V.D.; Patil, S.V. Aerosil-Supported Ionic Liquid Phase (ASILP) mediated synthesis of 2-substituted benzimidazole derivatives as AChE inhibitors. Chem. Sel. 2018, 3, 5544-5551. [CrossRef]

77. Brunig, J.; Csendes, Z.; Weber, S.; Gorgas, N.; Bittner, R.W.; Limbeck, A.; Bica, K.; Hoffmann, H.; Kirchner, K. Chemoselective Supported Ionic Liquid Phase (SILP) aldehyde hydrogenation catalysed by an Fe(II) PNP Pincer Complex. ACS Catal. 2018, 8, 1048-1051. [CrossRef]

78. Castro-Amoedo, R.; Csendes, Z.; Brunig, J.; Sauer, M.; Foelske-Schmitz, A.; Yigit, N.; Rupprechter, G.; Gupta, T.; Martins, A.M.; Bica, K.; et al. Carbon-based SILP catalysis for the selective hydrogenation of aldehydes using a well-defined Fe (II) PNP complex. Catal. Sci. Technol. 2018, 8, 4812-4820. [CrossRef]

79. Gajare, S.; Audumbar, P.; Kale, D.; Bansode, P.; Patil, P.; Rashinkar, G. Graphene oxide-supported ionic Liquid Phase catalysed synthesis of 3,4-dihydro-2H-naphtho[2,3-e][1,3]oxazine-5,10-diones. Chem. Lett. 2019, 150, 243-255.

80. Urban, B.; Skoda-Foldes, R. Development of palladium catalysts immobilized on supported phosphonium ionic liquid phases. Phosphorus Sulfur. 2019, 194, 302-306. [CrossRef]

81. Lee, C.; Sanding, B.; Buchmeiser, M.R.; Haumann, M. Supported Ionic Liquid Phase (SILP) facilitated gas-phase enzyme catalysis- CALB catalysed trensestrification of vinyl propionate. Catal. Sci. Technol. 2018, 8, 2460-2466. [CrossRef]

82. Wolf, P.; Logemann, M.; Schorner, M.; Keller, L.; Haaumann, M.; Wessling, M. Multi-walled carbo nanotube-based composite materials as catalyst support for water-gas shift and hydroformylation reactions. RSC Adv. 2019, 9, 27732-27742. [CrossRef]

83. Wolf, P.; Aubermann, M.; Wolf, M.; Bauer, T.; Blaumeiser, D.; Stepic, R.; Wick, C.R.; Smith, D.M.; Smith, A.S.; Wasserscheid, P.; et al. Improving the performance of supported ionic liquid phase (SILP) catalysts for the ultra-low-temperature water-gas shift reaction using metal salt additives. Green Chem. 2019, 21, 5008-5018. [CrossRef]

84. Bryzhin, A.A.; Gantman, M.G.; Buryak, A.K.; Tarkhanova, I.G. Brönsted acidic SILP-based catalysts with $\mathrm{H}_{3} \mathrm{PMo}_{12} \mathrm{O}_{40}$ i $\mathrm{H}_{3} \mathrm{PW}_{12} \mathrm{O}_{40}$ in the oxidative desulfurization of fuels. Appl. Catal. B Env. 2019, 257, 117938-117945. [CrossRef]

85. El Sayed, S.; Bordet, A.; Weidenthaler, C.; Hetaba, W.; Luska, K.L.; Leitner, W. Selective hydrogenation of benzofurans using ruthenium nanoparticles in Lewis acid-modifies Ruthenium-Supported Ionic Liquid Phase. ACS Catal. 2020, 10, 2124-2130. [CrossRef]

86. Kukawka, R.; Pawlowska-Zygarowicz, A.; Dzialkowska, J.; Pietrowski, M.; Maciejewski, H.; Bica, K.; Smiglak, M. Highly effective Supported Ionic Liquid-Phase (SILP) catalysts: Characterization and application to the hydrosilylation reaction. Sustain. Chem. Eng. 2019, 7, 4699-4706. [CrossRef]

87. Steinruck, H.P.; Wasserscheid, P. Ionic liquids in catalysis. Catal. Lett. 2015, 145, 380-397. [CrossRef]

88. Kernchen, U.; Etzold, B.; Korth, W.; Jess, A. Solid Catalyst with Ionic Liquid Layer (SCILL)- a new concept to improve the selectivity investigated for the example of hydrogenation of cyclooctadiene. Chem. Eng. Technol. 2007, 79, 807-819.

89. Werner, S.; Szesni, N.; Kaiser, M.; Haumann, M.; Wasserscheid, P. A scalable preparation method for SILP and SCILL ionic liquid thin-film materials. Chem. Eng. Technol. 2012, 11, 1962-1967. [CrossRef]

90. Miller, S.F.; Friedrich, H.B.; Holzapfel, C.W. The effects of SCILL catalyst modification on the competitive hydrogenation of 1-octyne and 1,7-octadiene versus 1-octene. ChemCatChem 2012, 4, 1337-1344. [CrossRef]

91. Antonels, N.C.; Meijboom, R. Preparation of well-defined dendrimer encapsulated ruthenium nanoparticles and their application as catalyst and enhancement of activity when utilised as SCILL catalysts in the hydrogenation of citral. Catal. Commun. 2014, 57, 148-152. [CrossRef] 
92. Antonels, N.C.; Williams, M.B.; Mejboom, R.; Haumann, M. Well-defined dendrimer encapsulated ruthenium SCILL catalysts for partial hydrogenation of toluene in liquid-phase. J. Mol. Catal. A Chem. 2016, 421, 156-160. [CrossRef]

93. Jalal, A.; Uzun, A. An exceptional selectivity for partial hydrogenation on a supported nickel catalyst coated with [BMIM] $\left[\mathrm{BF}_{4}\right]$. J. Catal. 2017, 350, 86-96. [CrossRef]

94. Lijewski, M.; Hogg, J.M.; Swadzba-Kwasny, M.; Wasserscheid, P.; Haumann, M. Coating of PD/C catalysts with Lewis-acidic ionic liquids and liquid coordination complexes-SCILL induced activity enhancement in arene hydrogenation. RSC Adv. 2017, 7, 27558-27563. [CrossRef]

95. Bart, T.; Korth, W.; Jess, A. Selectivity-enhancing effect of a SCILL catalyst in butadiene hydrogenation. Chem. Eng. Technol. 2017, 40, 395-404. [CrossRef]

96. Hu, S.; Wang, L.; Chen, X.; Wei, X.; Tong, Z.; Yin, L. The conversion of $\alpha$-pinene to cis-pinane using a nickel catalyst supported on a discarded fluid catalytic cracking catalyst with an ionic liquid layer. RSC Adv. 2019, 9, 5978-5986. [CrossRef]

97. Bauer, T.; Hager, V.; Williams, M.B.; Laurin, M.; Dopper, T.; Gorling, A.; Szesni, N.; Wassercheid, P.; Haumann, M.; Libuda, J. Palladium-mediated ethylation of the imidazolium cation monitored in-operando on a SCILL-type catalyst. ChemCatChem 2017, 9, 109-113. [CrossRef]

98. Perdikaki, A.V.; Vangeli, O.C.; Karanikolos, G.N.; Stefanopoulos, K.L.; Beltsios, K.G.; Alexandridis, P.; Kanellopoulus, N.K.; Romanos, G.E. Ionic liquid-modified porous materials for gas separation and heterogenous catalysis. J. Phys. Chem. C 2012, 31, 16398-16411. [CrossRef]

99. Podolean, I.; Pavel, O.D.; Manyar, H.G.; Taylor, S.F.R.; Ralphs, K.; Goodrich, P.; Parvulescu, V.I.; Hardacre, C. SCILLs as selective catalysts for oxidation of aromatic alcohols. Catal. Today 2019, 333, 140-146. [CrossRef]

100. Pavel, O.D.; Podolean, I.; Parvulescu, V.I.; Taylor, S.F.R.; Manyar, H.; Ralphs, K.; Goodrich, P.; Hardacre, C. Impact of SCILL catalysts for the S-S coupling of thiols to disulfides. Faraday Discuss. 2018, 206, 535-547. [CrossRef] [PubMed]

101. Mayer, C.; Hager, V.; Schwieger, W.; Wasserscheid, P. Enhanced activity and selectivity in n-octane isomerization using a bifunctional SCILL catalyst. J. Catal. 2012, 292, 157-165. [CrossRef]

102. Li, T.; Zhang, W.; Chen, W.; Miras, H.N.; Song, Y.F. Layered double hydroxide anchored ionic liquids as amphiphilic heterogeneous catalysts for the Knoevenagel condensation reaction. Dalton Trans. 2018, 47, 3059-3067. [CrossRef]

103. O’Reilly, N.; Giri, N.; James, S.L. Porous liquids. Chem. Eur. J. 2007, 13, 3020-3025. [CrossRef]

104. Zhang, S.; Dokko, K.; Watanabe, M. Porous ionic liquids: Synthesis and application. Chem. Sci. 2015, 6, 3684-3691. [CrossRef]

105. Wilke, A.; Yuan, J.; Antonietti, M.; Weber, J. Enhanced Carbon Dioxide Adsorption by a Mesoporous Poly(ionic liquid). ACS Macro Lett. 2012, 1, 1028-1031. [CrossRef]

106. Huang, J.; Tao, C.; An, Q.; Zhang, W.; Wu, Y.; Li, X.; Shen, D.; Li, G. Visual indication of enviromental humidity by using poly(ionic liquid) photonic crystals. Chem. Commun. 2010, 46, 4103-4105. [CrossRef]

107. Eftekhari, A. Polymerized Ionic Liquids. R. Soc. Chem. 2018, 2, $23-82$.

108. Jang, J.; Bae, J. Fabrication of mesoporous polymer using soft template method. Chem. Commun. 2005, 1200-1202. [CrossRef] [PubMed]

109. Liu, F.; Wang, L.; Sun, Q.; Zhu, L.; Meng, X.; Xiao, F.S. Transesterification Catalysed by Ionic Liquids on Superhydrophobic Mesoporous Polymers: Heterogeneous Catalysts That Are Faster than Homogeneous Catalysts. J. Am. Chem. Soc. 2012, 134, 16948-16950. [CrossRef] [PubMed]

110. Zhao, Q.; Dunlop, J.W.C.; Qiu, X.; Huang, F.; Zhang, Z.; Heyda, J.; Dziubiella, J.; Antonielli, M.; Yuan, J. An instant multi-responsive porous polymer actuator driven by solvent molecule sorption. Nat. Commun. 2014, 5, 4293-4300. [CrossRef] [PubMed]

111. Zhao, Q.; Heyda, J.; Dziubiella, J.; Tauber, K.; Dunlop, J.W.C.; Yuan, J. Sensing solvents with ultrasensitive porous poly(ionic liquid) actuators. Adv. Mater. 2015, 27, 2913-2917. [CrossRef] [PubMed]

112. Yu, Y.; Hu, T.; Chen, X.; Xu, K.; Zhang, J.; Huang, J. Pd nanoparticles on a porous ionic copolymer: A highly active and recyclable catalyst for Suzuki-Miyaura reaction under air in water. Chem. Commun. 2011, 47, 3592-3594. [CrossRef] [PubMed]

113. Zhao, P.; Leng, Y.; Wang, J. Heteropolyanion-paired cross-linked ionic copolymer: An efficient heterogeneous catalyst for hydroxylation of benzene with hydrogen peroxide. Chem. Eng. J. 2012, 204-206, 72-78. [CrossRef] 
114. Zhao, Q.; Zhang, P.; Antonielli, M.; Yuan, J. Poly(ionic liquid) complex with spontaneous micro-mesoporosity: Template-free synthesis and application as catalyst support. J. Am. Chem. Soc. 2012, 134, 11852-11855. [CrossRef]

115. Gao, C.; Chen, G.; Wang, X.; Li, J.; Zhou, Y.; Wang, J. Hierarchical meso-macroporous poly(ionic liquid) monolith derived from single soft template. Chem. Commun. 2015, 51, 4969-4972. [CrossRef]

116. Wang, B.; Sheng, X.; Zhou, Y.; Zhu, Z.; Liu, Y.; Sha, X.; Zhang, C.; Gao, H. Functional mesoporous poly(ionic liquid) derived from P123: From synthesis to catalysis and alkylation of styrene and o-xylene. Appl. Organomet. Chem. 2019, 33, 4719-4730. [CrossRef]

117. Sheng, X.; Gao, H.; Zhou, Y.; Wang, B.; Sha, X. Stable poly (ionic liquids) with unique cross-linked mesoporous-macroporous structure as efficient catalyst for alkylation of $o$-xylene and styrene. Appl. Organomet. Chem. 2019, 33, 4979-4989. [CrossRef]

118. Wang, X.; Li, J.; Chen, G.; Guo, Z.; Zhou, Y.; Wang, J. Hydrophobic mesoporous poly(ionic liquid)s towards highly efficient and contamination-resistant solid-base catalyst. ChemCatChem 2015, 6, 993-1003. [CrossRef]

119. Tao, D.J.; Liu, F.; Wang, L.; Jiang, L. A green and efficient hydration of alkynes catalysed by hierarchically porous poly(ionic liquid)s solid strong acids. Appl. Catal. A Gen. 2018, 564, 56-63. [CrossRef]

120. Hui, W.; Heb, X.M.; Xua, X.Y.; Chen, Y.M.; Zhou, Y.; Li, Z.M.; Zhang, L.; Tao, D.J. Highly efficient cycloaddition of diluted and waste $\mathrm{CO}_{2}$ into cyclic carbonates catalyzed by porous ionic copolymers. J. $\mathrm{CO}_{2}$ Util. 2020, 36, 169-176. [CrossRef]

121. Wang, Y.; Guo, L.; Yin, L. Progress in the Heterogeneous Catalytic Cyclization of $\mathrm{CO}_{2}$ with Epoxides Using Immobilized Ionic Liquids. Catal. Lett. 2019, 149, 985-997. [CrossRef]

122. Fujie, K.; Yamada, T.; Ikeda, R.; Kitagawa, H. Introduction of an ionic liquid into the micropores of a metal-organic framework and its anomalous phase behavior. Angew. Chem. Int. Ed. 2014, 53, 11302-11305. [CrossRef]

123. Luo, Q.X.; An, B.W.; Ji, M.; Park, S.E.; Hao, C.; Li, Y.Q. Metal-organic frameworks HKUST-1 as porous matrix for encapsulation of basic ionic liquid catalyst: Effect of chemical behaviour of ionic liquid in solvent. J. Porous Mater. 2015, 22, 247-259. [CrossRef]

124. Luo, Q.; Song, X.; Ji, M.; Park, S.E.; Hao, C.; Li, Y. Molecular size- and shape-selective Knoevenagel condensation over microporous $\mathrm{Cu}_{3}(\mathrm{BTC})_{2}$ immobilized amino-functionalized basic ionic liquid catalyst. Appl. Catal. A 2014, 478, 81-90. [CrossRef]

125. Fujie, K.; Kitagawa, H. Ionic liquid transported into metal-organic frameworks. Coord. Chem. Rev. 2016, 307, 382-390. [CrossRef]

126. Khan, N.A.; Hasan, Z.; Jhung, S.H. Ionic liquid@MIL-101 prepared via the ship-in-bottle technique: Remarkable adsorbents for the removal of benzothiophene from liquid fuel. Chem. Commun. 2016, 52, 2561-2564. [CrossRef]

127. Fujie, K.; Otsubo, K.; Ikeda, R.; Yamada, T.; Kitagawa, H. Low temperature ionic conductor: Ionic liquid incorporated within a metal-organic framework. Chem. Sci. 2015, 6, 4306-4310. [CrossRef]

128. Sun, Y.; Jia, X.; Huang, H.; Guo, X.; Qiao, Z.; Zhong, C. Solvent-free mechanochemical route for the construction of ionic liquid and mixed-metal MOF composites for synergistic $\mathrm{CO}_{2}$ fixation. J. Mater. Chem. A 2020, 8 , 3180-3185. [CrossRef]

129. Gomes, M.C.; Pison, L.; Cervinka, C.; Padua, A. Porous Ionic Liquids or Liquid Metal-Organic Frameworks? Angew. Chem. Int. Ed. 2018, 57, 11909-11912. [CrossRef] [PubMed]

130. Ferreira, T.J.; Ribeiro, R.P.P.L.; Mota, J.P.B.; Rebelo, L.P.N.; Esperança, J.M.S.S.; Esteves, I.A.A.C. Ionic Liquid-Impregnated Metal-Organic Frameworks for $\mathrm{CO}_{2} / \mathrm{CH}_{4}$ Separation. ACS Appl. Nano Mater. 2019, 2, 7933-7950. [CrossRef]

131. Liu, S.; Liu, J.; Hou, X.; Xu, T.; Tong, J.; Zhang, J.; Ye, B.; Liu, B. Porous Liquid: A Stable ZIF-8 Colloid in Ionic Liquid with Permanent Porosity. Langmuir 2018, 34, 3654-3660. [CrossRef]

132. Ma, L.; Haynes, C.J.E.; Grommet, A.B.; Walczak, A.; Parkins, C.C.; Doherty, C.M.; Longley, L.; Tron, A.; Stefankiewicz, A.R.; Bennett, T.D.; et al. Coordination cages as permanently porous ionic liquids. Nat. Chem. 2020, 12, 270-275. [CrossRef]

133. Prechtl, M.H.G. (Ed.) Nanocatalysis in Ionic Liquids; Wiley-VCH: Weinheim, Germany, 2017.

134. Verma, C.; Ebenso, E.E.; Quraishi, M.A. Transition metal nanoparticles in ionic liquids: Synthesis and stabilization. J. Mol. Liq. 2019, 276, 826-849. [CrossRef] 
135. Hesemann, P. Applications of ionosilicas in heterogeneous catalysis: Opportunities for the elaboration of new functional catalytic phases. Curr. Opin. Green Sustain. Chem. 2018, 10, 21-26. [CrossRef]

136. Rajendran, A.; Rajendiran, M.; Yang, Z.F.; Fan, H.X.; Cui, T.Y.; Zhang, Y.G.; Li, W.Y. Functionalized Silicas for Metal-Free and Metal-Based Catalytic Applications: A Review in Perspective of Green Chemistry. Chem. Rec. 2019, 19, 1-29. [CrossRef]

137. Mecerreyes, D. (Ed.) Applications of Ionic Liquids in Polymer Science and Technology; Springer: Heidelberg, Germany, 2015.

138. Li, P.; Cheng, F.-F.; Xiong, W.-W.; Zhang, Q. New synthetic strategies to prepare metal-organic frameworks. Inorg. Chem. Front. 2018, 5, 2693-2708. [CrossRef]

139. Kore, R.; Berton, P.; Kelley, S.P.; Aduri, P.; Katti, S.S.; Rogers, R.D. Group IIIA halometallate ionic liquids: Speciation and applications in catalysis. ACS Catal. 2017, 7, 7014-7028. [CrossRef]

140. Jankowska-Wajda, M.; Bartlewicz, O.; Walczak, A.; Stefankiewicz, A.R.; Maciejewski, H. Highly efficient hydrosilylation catalysts based on chloroplatinate "ionic liquids". J. Catal. 2019, 374, 266-275. [CrossRef]

141. Zhang, H.; Xu, C.C.; Yang, S. Heterogeneously chemo/enzyme-functionalized porous polymeric catalysts of high-performance for efficient biodiesel production. ACS Catal. 2019, 9, 10990-11029. [CrossRef]

Publisher's Note: MDPI stays neutral with regard to jurisdictional claims in published maps and institutional affiliations.

(C) 2020 by the authors. Licensee MDPI, Basel, Switzerland. This article is an open access article distributed under the terms and conditions of the Creative Commons Attribution (CC BY) license (http://creativecommons.org/licenses/by/4.0/). 